Journal of the Scholarship of Teaching and Learning, Vol. 20, No. 2, October 2020, pp. 113-121.

doi: 10.14434/josotl.v20i2.25777

\title{
Augmented Reality Facilitated Scavenger Hunt for Mobile Learning
}

\author{
Lan $\mathbf{L i}$ \\ Bowling Green State University \\ 1li@bgsu.edu
}

\begin{abstract}
Game-based learning has become increasingly popular in recent years and has drawn an increasing level of attention in education. While the preliminary findings of educational gaming impact are quite promising, the current dilemma is the disconnect between what is available on the market and what is needed in the classroom. There has been an increasing call for teachers to be game designers to create educational games that tailor to their specific instructional needs. This paper shares one example how an educator, performing both roles as class teacher and game designer, utilized Augmented Reality and mobile learning to modernize a traditional scavenger bunt to engage students and promote their learning. It is the author's hope that this paper would encourage more educators to explore, experiment, and discover how game-based learning may be effectively utilized in their classrooms.
\end{abstract}

Keywords: game-based learning, game design, mobile learning, student engagement

\section{Game-Based Learning}

Gaming has made interesting inroads in education. Many educators and researchers believe that educational games may transform teaching and learning in ways that we could never imagine before. The recently coined term "edutainment" highlights the emergence that combines both aspects of education and entertainment (Purdy, 2007). Game-based learning has made considerable strides in classroom adoptions.

Game-based learning is defined as the integration of gaming elements in education to achieve defined academic outcomes (Kirriemuir \& McFarlane, 2004; McGonigal, 2011). Simply put, gamebased learning is learning through games, either digital or non-digital. Although the potential benefits of game-based learning have not yet been fully examined and established, the preliminary findings in literature seem to suggest that effectively integrated game-based learning may have a positive impact on students' learning effectiveness and motivation (e.g., Kirikkaya, Iseri, \& Vurkaya, 2010; Lin et al., 2013; Papastergiou, 2009; Yien, Hung, Hwang, \& Lin, 2011). A growing number of studies further indicate that adoption of gaming features in curricula may help promote students' higher-order skills such as critical thinking (e.g. Cicchino, 2013; Carbonaro, Szafron, Cutumisu, \& Schaeffer, 2010), cultivate self-awareness (e.g. Yang, Chien \& Liu, 2012), enhance interest in subject areas (e.g. Glushkova, 2016), and increase germane cognitive loads, and may also reduce extraneous cognitive loads (e.g. Chang, Liang, Chou \& Lin, 2017), etc. With these encouraging results, using games as a tool to facilitate teaching and foster learning has gained increased acceptance in education. Studies have shown that educators view digital games as viable motivational, collaborative, and instructional tools (e.g. Noraddin \& Kian, 2015).

For game-based learning to be effective, gaming features and education content need to complement each other. It is unlikely that "game designers can bypass educators to reach students directly and revolutionize their learning experiences" (Kwek, 2015). One big challenge that the educational gaming field faces is a substantive lack of understanding between what game designers create and what educators desire (Schifter, 2013). Game designers possess the skills of developing engaging and motivating games, but many are deficient in content knowledge. In contrast, teachers, 
as content experts, may need assistance in unlocking the full potential of gaming in education (Squire, 2008). To bridge the disconnect, there has been an increasing call for teachers as game designers (Osman \& Bakar, 2013; Sandford, 2014). There remain, however, questions about if and how teachers could seamlessly switch back and forth from one role to the other on demand and develop engaging games to cater to their instructional needs. Existing models or examples demonstrating teachers' "dual-role play" are scarce in literature. The purpose of this paper, therefore, is to share my experience, as a classroom teacher, of leveraging one of the latest technologies, Augmented Reality, to design and facilitate a mobile learning scavenger hunt game to facilitate students' content learning.

\section{Project Context and Participants}

The 21 students who participated in the scavenger hunt game were all pre-service teachers who enrolled in a technology application course in a mid-western university. Among reported, students ranged in age from 21 to 28, with an average age of 22.18. Students consisted of 11 females and 10 males. From previous class projects, students had all acquired knowledge about and skills of Augmented Reality and Google Forms. At the time of the game, they had just learned the concept of the WebQuest. The WebQuest is an Internet-based lesson model that integrates pre-selected web resources to engage students in tasks that challenge their higher-order thinking skills. In the past two decades, teacher preparation programs in the United States have adopted technology-utilized lesson models such as WebQuest as instructional frameworks to train pre-service teacher in integrating the Internet and web resources into curricula (Kundu \& Bain, 2006; Haralson, Hoaglund, Birkenfeld \& Rogers, 2016; Summerville, 2000). Wang and Hannafin (2008) state that "teacher educators have applied the WebQuest model with preservice teachers in order to develop technology integration skills akin to those used in everyday schools" (p. 59).

\section{Students' Roles in the Scavenger Hunt Game}

While I played dual roles as the class teacher and the game designer in this project, the students also played multiple roles as designers, players, and reflectors. As designers, the students created questions used in the hunt. As players, students worked in groups that competed with other groups in the game. As reflectors, students shared their game-based learning experience and reflected upon how they saw, as future teachers, that this type of educational games may be created and utilized in their specific subject areas to engage their students and foster learning.

The scavenger hunt activity was empowered by HP Reveal and Google Forms. HP Reveal, formerly known as Aurasma, is an Augmented Reality application that is available in both web format and as a downloadable app. HP Reveal allows users to overlay digital information such as images, videos, or websites on top of static images or real-world objects. These images or objects are called "trigger images" in HP Reveal. Scanning trigger images with cameras on smart devices would activate overlays and bring them to life. Many of us have watched Harry Potter movies in awe as pictures moved and news events on papers came alive. Now Augmented Reality makes it possible to integrate this kind of fantasy with learning, which immerses learners and sustains their attention. Google Forms is part of the Google Tools suite. Google Forms enables users to collect data and conduct online quizzes. The combination of these applications and mobile tablets have modernized the old-fashioned scavenger hunt game.

Journal of the Scholarship of Teaching and Learning, Vol. 20, No. 2, October 2020. josotl.indiana.edu 


\section{Role as Designer}

After students learned what the Webquest is and what a good Webquest consists of, they were instructed to construct questions for a scavenger game to challenge their peers' knowledge of WebQuests. A scavenger hunt is a game in which participants work with clues to solve a series of problems, complete a set of tasks, or locate a number of items (Scavenger Hunt, n.d.). In this study, student groups competed in the game to see which group would be able to correctly answer a set of questions or effectively solve a list of problems regarding various aspects of Webquests, therefore, be first to reach the final destination.

As designers, students were instructed to create appropriate but challenging questions that could engage their competing peers' brain muscles. The goal of creating rather "difficult" questions that were not easy to answer was to prevent competing groups from making progress. Thus, students could win the game themselves. Created questions varied in levels of difficulty from fact questions to higher-order questions that would go beyond simple recall or recognition of information. An example of a fact question is: "What is the correct order of components in a WebQuest?" An example of a higher-order questions is: "Emily is creating a Webquest that would help students to learn William Shakespeare and the time in which he lived. The following is a list of web resources Emily has gathered. Can you identify one resource that is NOT appropriate for her WebQuest and explain why?" The latter question required students to use their knowledge of not only WebQuest but also website evaluation, and possibly other domains as well. While working on solving the problem, students needed to use their analysis and evaluation skills to eliminate outdated, inappropriate, or irrelevant resources. Additionally, students needed to examine various resources and identify their relationship to the William Shakespeare WebQuest. During the process, discussions, clarifications, and minor or major revisions of questions occurred within each group.

The purpose of engaging students in the process of designing the questions was twofold: 1) Enhancing students' motivation. In the scavenger hunt activity, students were not only passive recipients of information or followers of instruction but active participants and constructors of the game-based learning. They had a say in what questions should be included in the game. The engagement would endow students with a sense of ownership 2). Promoting students' learning. In order to create relevant and appropriate questions to challenge their peers, students first needed to have a deep understanding of the content-WebQuest. The role of designer pushed students forward to learn the content.

\section{Role as Player}

The game started in the classroom (Station 1, see Figure 1), then moved to different locations on campus. In this specific scavenger hunt game, trigger images were printed in paper. Printed trigger images were placed on campus ahead of the game time. Each group was given a clue to find their first trigger image in Station 1. When a group of students used their smart devices to scan the first image, students would first activate a passage of text or a short video. The text or the video would explain the problem they needed to solve, provide students with clues, and connect students with content learned in class. Once students completed this step and decided to move forward, they would follow the instruction on the screen and tap the imbedded anchor. They would then be directed to a Google Forms page where they could answer a quiz-type question. If the group answered the question correctly, a message would appear on the screen of their devices directing students to the next station. However, as Figure 1 shows, if the group made a wrong choice, another question would pop up on screen to detain students in that station until they answered the question correctly or until they reached the last question embedded in that station. The process of answering additional questions was called

Journal of the Scholarship of Teaching and Learning, Vol. 20, No. 2, October 2020. josotl.indiana.edu 
"Station Detour" in this game, as it created a circuitous way to delay students' progress to get to their next stations. The first group that reached the final station (Station 5) and answered the question correctly won the game.

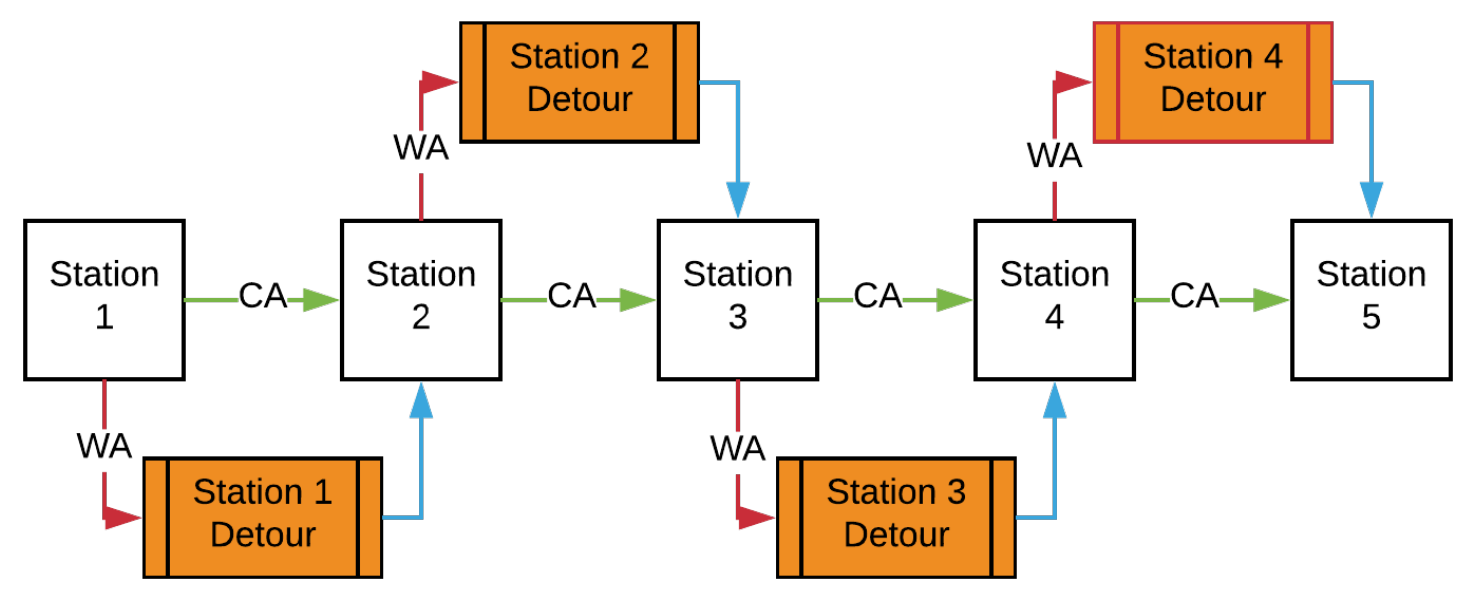

Note: $\mathrm{CA}=$ Correct Answer; WA=Wrong Answer

\section{Figure 1: Scavenger Hunt Route}

\section{Role as Reflector}

After completing the scavenger hunt game, students and I both participated in a class discussion to reflect upon our experiences in the project. I explored my learning process and challenges in this project, and also my view on how I saw my two roles, as classroom teacher and game designer, related to and supported each other. Students shared their thoughts and opinions regarding game integration in education. Three themes emerged from the class discussion. First, we thought that the scavenger hunt game was engaging and motivating. It was agreed that augmented reality and mobile learning integration in the game revived the old style of gameplay. Second, the value of learning through game design and play was recognized. Students' unique experience of participating in designing game questions to challenge their peers, and of competing with peer groups to win the game really engaged them and motivated them for deeper content learning. Third, it seemed that students' involvement in this game empowered them to view game-based learning from a new and different angle. As preservice teachers, quite a few students expressed their acceptance and approval of game-based learning in their respective subject areas. Some students never thought they could create educational games. And their engagement in this activity inspired their interest and future efforts in game design and learning. These themes emerged from class discussion were, to some extent, confirmed by students' feedback through an online questionnaire after their completion of the game activity.

\section{Student Feedback}

The short questionnaire included two subscales from the Intrinsic Motivation Inventory (IMI), which contains seven subscales and is a multidimensional scale intended to measure individuals' subjective experience related to experimental tasks (Intrinsic Motivation Inventory, n.d.). The questionnaire chose only two subscales from the inventory: Interest/Enjoyment subscale and Perceived Competence subscale, as I was interested in understanding how the game impacted students' intrinsic motivation and how well students felt they were prepared to participate in the activity. The 
Interest/Enjoyment subscale contained 7 items. Example items included, "I enjoyed doing this activity very much," and "I thought this activity was quite enjoyable." The Perceived Competence subscale included 6 items. Example items included, "I think I am pretty good at this activity," and "I am satisfied with my performance at the task." All items were rated on a seven-point Likert scale ranging from 1 (not at all true) to 7 (very true). In addition to the two IMI subscales, the questionnaire also included an open-ended question to elicit students' input regarding their perceived strengths and weaknesses of the Scavenger Hunt Game.

Table 1 shows the seven statements of the Intrinsic Motivation subscale. The maximum score, minimum score, mean score and standard deviation of each statement were reported in the table. Most students reported relatively high levels of intrinsic motivation to participate in the Scavenger Hunt game.

Table 1. Maximum Scores, Minimum Scores, Mean Scores and Standard Deviations of Student Intrinsic Motivation Subscale

\section{Items}

I enjoyed doing this activity very much.

This activity was fun to do.

I thought this was a boring activity (reverse scoring item).

This activity did not hold my attention at all (reverse scoring item).

I would describe this activity as very interesting.

I thought this activity was quite enjoyable.

While I was doing this activity, I was thinking about how much I enjoyed it.
$\operatorname{Max} \quad$ Min

4.00

2.00

1.00

2.00

1.02

5.00

5.00

1.00

1.95

7.00

3.00

5.43

1.33

7.00

3.00

5.48

1.22

7.00

2.00

4.38

1.84

Note. Max $=$ Maximum; Min $=$ Minimum $; \mathrm{M}=$ Mean $; \mathrm{SD}=$ Standard Deviation.

Table 2 shows the six statements of the Perceived Competence subscale. The maximum score, minimum score, mean score and standard deviation of each statement were reported in the table. Most students reported relatively high levels of perceived competence to participate in the Scavenger Hunt game.

Journal of the Scholarship of Teaching and Learning, Vol. 20, No. 2, October 2020. josotl.indiana.edu 
Table 2. Maximum Scores, Minimum Scores, Mean Scores and Standard Deviations of Student Perceived Competence Subscale

\section{Items}

I think I am pretty good at this activity.

I think I did pretty well at this activity, compared to other students.

After working at this activity for a while, I felt pretty 7.00 competent.

I am satisfied with my performance at this task.

I was pretty skilled at this activity.

This was an activity that I couldn't do very well 6.00 (reverse scoring item).
$\operatorname{Max}$

7.00

7.00

7.00

7.00
Min
$\mathbf{M}$

4.86
SD

Note. Max $=$ Maximum; Min $=$ Minimum $; \mathrm{M}=$ Mean $; \mathrm{SD}=$ Standard Deviation.

Students' responses to the open-ended question regarding their perceived strengths and weaknesses of the Scavenger Hunt Game were analyzed by two independent coders using a two-level process. At the first level, coders assigned one or more codes or tags to each response to help capture what the response was about. In the second level, coders reread the data to confirm identified concepts and categories. Codes were added, expanded or revised at this stage. Repeating themes emerged during this process. Two coders reviewed and agreed upon the resulted themes.

Four themes emerged from the data analysis. Two themes, Learning Engagement and Mobile Learning, were related to the strengths of the activity. Quite a few students stated that learning through the game was fun, interesting and engaging. Some students also appreciated that the game provided them with a unique learning experience to explore mobile learning. The other two themes, Group Participation and Length of Game, were related to students' perceived weaknesses of the activity. Some students expressed a few concerns of group work, mainly concerning tracking of group progress and participation in their respective groups. There were also a few students who suggested that the game was too short. To some extent, the last theme, Length of Game, could actually be a sign hinting that these students might have enjoyed the game and they wished it could be longer. Table 3 presents some sample direct quotes under each theme. 
Table 3. Students' Perceived Strengths and Weaknesses of the Scavenger Hunt Game: Themes and Sample Quotes

\section{Themes}

\author{
Mobile Learning \\ "...getting students \\ outside the classroom \\ provides a unique \\ learning experience." \\ "It allows students to \\ be mobile and move \\ around the campus \\ and still be engaged in \\ learning." \\ "A downside is you \\ can't really track them \\ [groups] so they could \\ just never come back." \\ “...some groups were \\ not open to allowing \\ [other] students to \\ work with \\ them...unless the \\ teacher could assign \\ group members to \\ make everything fair."
}

\section{Length of Game}

"It [the game] was a bit short."

"I would make it have more clues in more locations if it was done again."

\section{Conclusion}

This paper reports my experience of designing and implementing an invigorated scavenger hunt that was brought up to date with augmented reality and mobile learning in a technology application course in teacher education. Both students and I served multiple roles in this project. The class discussion and results of the post activity questionnaire suggest that students, in general, enjoyed the modernized scavenger hunt game and acknowledged the learning experience. Based on students' feedback, future scavenger hunt games should probably integrate more activities and involve more stations. In addition, special consideration should be paid to ensure active and effective group participation from each student.

While the modernized scavenger hunt game may possibly incorporate other technologies such as QR codes to allow students interact with the multimedia elements embedded in the game and complete the quiz questions, integrating Augmented Reality certainly makes the game more fun, fulfilling, and immersive. Augmented Reality might sound quite advanced and expensive for classroom use. However, user friendly applications such as HP Reveal and abundant hands-on tutorials have made the technology affordable and accessible for educators.

The fast-changing technological world has successfully blurred the distinctions between various roles that we play. My role as teacher and game designer and students' roles as game designer, game player, and reflector impeccably intertwined and supported each other in this project. It is my hope this the sharing of this project will encourage other educators to explore game-based learning and the ways that educators may design and create their very own games that tailor to their very own instructional needs. The advance and ease of use of technologies certainly make this mission possible.

Journal of the Scholarship of Teaching and Learning, Vol. 20, No. 2, October 2020. josotl.indiana.edu 


\section{References}

Chang, C. C., Liang, C., Chou, P. N., \& Lin, G. Y. (2017). Is game-based learning better in flow experience and various types of cognitive load than non-game-based learning? Perspective from multimedia and media richness. Computers in Human Behavior, 71, 218-227.

Cicchino, M. I. (2013). Using game-based learning to foster critical thinking in student discourse. Rutgers The State University of New Jersey-New Brunswick.

Carbonaro, M., Szafron, D., Cutumisu, M., \& Schaeffer, J. (2010). Computer-game construction: A gender-neutral attractor to Computing Science. Computers \& Education, 55(3), 1098-1111.

Glushkova, T. (2016). Application of Block Programming and Game-Based Learning to Enhance Interest in Computer Science. Journal of Innovations and Sustainability, 2(1), 21-32.

Haralson, M., Hoaglund, A., Birkenfeld, K., \& Rogers, B. (2016). Using WebQuests to support preservice teachers' attitudes toward diversity: a model for the future. Education, 136(4), 413-420.

Intrinsic Motivation Inventory. (n.d.). Retrieved from http://selfdeterminationtheory.org/intrinsicmotivation-inventory/

Kirriemuir, J., \& McFarlane, A. (2004). Literature review in games and learning. Futurelab. Retrieved from https://telearn.archives-ouvertes.fr/hal-00190453/document

Kirikkaya, E. B., Iseri, S., \& Vurkaya, G. (2010). A board game about space and solar system for primary school students. Turkish Online Journal of Education Technology, 9(2), 1-13.

Lin, C. H., Liu, E. Z. F., Chen, Y. L., Liou, P. Y., Chang, M., Wu, C. H., \& Yuan, S. M. (2013). Gamebased remedial instruction in mastery learning for upper-primary school students. Educational Technology \& Society, 16(2), 271-281.

McGonigal, J. (2011). Reality is broken: Why games make us better and bow they can change the world. New York: Penguin.

Noraddin, E., \& Kian, N. T. (2015). Three learning potentials in digital games: perception of Malaysian university teachers. Journal of e-Learning and Knowledge Society, 11(2), 143-160.

Kundu, R., \& Bain, C. (2006). Webquests: Utilizing technology in a constructivist manner to facilitate meaningful preservice learning. Art Education, 59(2), 6-11.

Kwek, S. H. (2011). Innovation in the classroom: Design thinking for 21st century learning. Retrieved from https://web.stanford.edu/group/redlab/cgi-bin/materials/KwekInnovation $\% 20 I n \% 20$ The $\% 20$ Classroom.pdf

Osman, K., \& Bakar, N. A. (2013). Teachers and students as game designers: Designing games for classroom integration. New Pedagogical Approaches in Game Enhanced Learning: Curriculum Integration, 102-113.

Papastergiou, M. (2009). Digital game-based learning in high school computer science education: Impact on educational effectiveness and student motivation. Computers and Education, 52(1), 112.

Purdy, J. A. (2007). Getting educational about digital games in learning. Corporative University Journal, 1, 3-6.

Schifter, C. C. (2013). Games in learning, design, and motivation. In M. Murphy, S. Redding, \& J. Twyman (Eds.), Handbook on innovations in learning (pp. 149-164). Philadelphia, PA: Center on Innovations in Learning, Temple University; Charlotte, NC: Information Age Publishing. Retrieved from http://www.centeril.org/

Squire, K. D. (2008). Video games and education: Designing learning systems for an interactive age. Educational Technology, 48(2), 17-26.

Sandford, R. (2014). Teachers as game designers: using a game in formal learning in a Singapore primary school. Educational Media International, 51(1), 66-78.

Summerville, J. (2000). WebQuests. TechTrends, 44(2), 31-35.

Journal of the Scholarship of Teaching and Learning, Vol. 20, No. 2, October 2020.

josotl.indiana.edu 
Wang, F., \& Hannafin, M. J. (2008). Integrating WebQuests in preservice teacher education. Educational Media International, 45(1), 59-73.

Yang, J. C., Chien, K. H., \& Liu, T. C. (2012). A digital game-based learning system for energy education: an energy conservation pet. The Turkish Online Journal of Educational Technology, 11(2), $29-37$.

Yien, J. M., Hung, C. M., Hwang, G. J., \& Lin, Y. C. (2011). A game-based learning approach to improving students' learning achievements in a nutrition course. The Turkish online journal of educational technology, 10(2), 1-10.

Journal of the Scholarship of Teaching and Learning, Vol. 20, No. 2, October 2020.

josotl.indiana.edu 